University of Nebraska - Lincoln

DigitalCommons@University of Nebraska - Lincoln

Michigan Bovine Tuberculosis Bibliography and Database

Wildlife Disease and Zoonotics

2008

\title{
Animal-side serologic assay for rapid detection of Mycobacterium Bovis infection in multiple species of free-ranging wildlife
}

\author{
K.P. Lyashchenko \\ Chembio Diagnostic Systems, Inc., 3661 Horseblock Road, Medford, NY 11763, USA \\ R. Greenwald \\ Chembio Diagnostic Systems, Inc., 3661 Horseblock Road, Medford, NY 11763, USA \\ J. Esfandiari \\ Chembio Diagnostic Systems, Inc., 3661 Horseblock Road, Medford, NY 11763, USA
}

\author{
M.A. Chambers \\ TB Research Group, Department of Statutory and Exotic Bacterial Diseases, Veterinary Laboratories \\ Agency Weybridge, New Haw, Surrey KT15 3NB, UK \\ J. Vicente \\ Instituto de Investigacion en Recursos Cinegeticos IREC (CSIC-UCLM-JCCM), Ciudad Real, Spain \\ See next page for additional authors \\ Follow this and additional works at: https://digitalcommons.unl.edu/michbovinetb \\ Part of the Veterinary Medicine Commons
}

Lyashchenko, K.P.; Greenwald, R.; Esfandiari, J.; Chambers, M.A.; Vicente, J.; Gortazar, C.; Santos, N.; Correia-Neves, M.; Buddle, B.M.; Jackson, R.; O’Brien, D.J.; Schmitt, S.; Palmer, M. V.; Delahay, R.J.; and Waters, W.R., "Animal-side serologic assay for rapid detection of Mycobacterium Bovis infection in multiple species of free-ranging wildlife" (2008). Michigan Bovine Tuberculosis Bibliography and Database. 48.

https://digitalcommons.unl.edu/michbovinetb/48

This Article is brought to you for free and open access by the Wildlife Disease and Zoonotics at DigitalCommons@University of Nebraska - Lincoln. It has been accepted for inclusion in Michigan Bovine Tuberculosis Bibliography and Database by an authorized administrator of DigitalCommons@University of Nebraska Lincoln. 


\section{Authors}

K.P. Lyashchenko, R. Greenwald, J. Esfandiari, M.A. Chambers, J. Vicente, C. Gortazar, N. Santos, M. Correia-Neves, B.M. Buddle, R. Jackson, D.J. O’Brien, S. Schmitt, M. V. Palmer, R.J. Delahay, and W.R. Waters 


\title{
Animal-side serologic assay for rapid detection of Mycobacterium bovis infection in multiple species of free-ranging wildlife
}

\author{
K.P. Lyashchenko ${ }^{\text {a } *}$, R. Greenwald ${ }^{\text {a }}$, J. Esfandiari ${ }^{\text {a }}$, M.A. Chambers ${ }^{b}$, J. Vicente ${ }^{c}$, \\ C. Gortazar ${ }^{\text {c }}$, N. Santos ${ }^{\text {d,e }}$, M. Correia-Neves ${ }^{\text {e }}$, B.M. Buddle ${ }^{f}$, R. Jackson ${ }^{g}$, \\ D.J. O’Brien $^{\text {h }}$, S. Schmitt ${ }^{\text {h }}$, M.V. Palmer ${ }^{\mathrm{i}}$, R.J. Delahay ${ }^{\mathrm{j}}$, W.R. Waters ${ }^{\mathrm{i}}{ }^{\text {, }}$ \\ ${ }^{\text {a } C h e m b i o ~ D i a g n o s t i c ~ S y s t e m s, ~ I n c ., ~} 3661$ Horseblock Road, Medford, NY 11763, USA \\ ${ }^{\mathrm{b}}$ TB Research Group, Department of Statutory and Exotic Bacterial Diseases, Veterinary Laboratories Agency Weybridge, \\ New Haw, Surrey KT15 3NB, UK \\ ${ }^{\mathrm{c}}$ Instituto de Investigacion en Recursos Cinegeticos IREC (CSIC-UCLM-JCCM), Ciudad Real, Spain \\ ${ }^{\mathrm{d}}$ Faculty of Veterinary Medicine, Lisbon, Portugal \\ ${ }^{\mathrm{e}}$ Life and Health Sciences Research Institute (ICVS), School of Health Sciences, University of Minho, Braga, Portugal \\ ${ }^{\mathrm{f}}$ AgResearch, Hopkirk Research Institute, Palmerston North, New Zealand \\ ${ }^{\mathrm{g}}$ Institute of Veterinary, Animal \& Biomedical Sciences, Massey University, Palmerston North, New Zealand \\ ${ }^{\mathrm{h}}$ Wildlife Disease Laboratory, Department of Natural Resources, Lansing, MI, USA \\ ${ }^{\mathrm{i}}$ United States Department of Agriculture (USDA), Agricultural Research Service, National Animal Disease Center, \\ Bacterial Diseases of Livestock Research Unit, National Animal Disease Center, Ames, IA, USA \\ ${ }^{\mathrm{j}}$ Wildlife Disease Ecology Team, Central Science Laboratory, Sand Hutton, York YO41 1LZ, UK
}

Received 7 April 2008; received in revised form 20 May 2008; accepted 26 May 2008

\begin{abstract}
Numerous species of mammals are susceptible to Mycobacterium bovis, the causative agent of bovine tuberculosis (TB). Several wildlife hosts have emerged as reservoirs of $M$. bovis infection for domestic livestock in different countries. In the present study, blood samples were collected from Eurasian badgers $(n=1532)$, white-tailed deer $(n=463)$, brushtail possums ( $n=129)$, and wild boar $(n=177)$ for evaluation of antibody responses to M. bovis infection by a lateral-flow rapid test (RT) and multiantigen print immunoassay (MAPIA). Magnitude of the antibody responses and antigen recognition patterns varied among the animals as determined by MAPIA; however, MPB83 was the most commonly recognized antigen for each host studied. Other seroreactive antigens included ESAT-6, CFP10, and MPB70. The agreement of the RT with culture results varied from $74 \%$ for possums to $81 \%$ for badgers to $90 \%$ for wild boar to $97 \%$ for white-tailed deer. Small numbers of wild boar and deer exposed to M. avium infection or paratuberculosis, respectively, did not cross-react in the RT, supporting the high specificity of the assay. In deer, whole blood samples reacted similarly to corresponding serum specimens ( $97 \%$ concordance), demonstrating the potential for field application. As previously demonstrated for badgers and deer, antibody responses to M. bovis infection in wild boar were positively associated with advanced disease. Together, these findings suggest that a rapid TB assay such as the RT
\end{abstract}

\footnotetext{
* Corresponding author. Tel.: +1 631924 1135; fax: +1 6319246033.

E-mail address: klyashchenko@chembio.com (K.P. Lyashchenko).
} 
may provide a useful screening tool for certain wildlife species that may be implicated in the maintenance and transmission of $M$. bovis infection to domestic livestock.

(C) 2008 Elsevier B.V. All rights reserved.

Keywords: Tuberculosis; Mycobacterium bovis; Wildlife; Serology

\section{Introduction}

Bovine tuberculosis (TB) remains an important zoonotic disease with significant impacts on the economy in many countries (Corner, 2006; Cosivi et al., 1998; Michel et al., 2006). Several wild mammal species are implicated in the maintenance and transmission of Mycobacterium bovis infection and thereby impede national bovine TB control programs and international trade (Cousins, 2001; Palmer, 2007). Well-known examples of wildlife maintenance hosts include Eurasian badgers (Meles meles) in Great Britain and Ireland (Clifton-Hadley et al., 1993; Griffin et al., 2005), white-tailed deer (Odocoileus virginianus) in the United States (Schmitt et al., 1997; O'Brien et al., 2002, 2006), brushtail possums (Trichosurus vulpecula) in New Zealand (Coleman et al., 2006; Porphyre et al., 2007), wild boar (Sus scrofa) in Spain (Gortázar et al., 2003; Naranjo et al., 2008), and African buffalo (Syncerus caffer) in South Africa (Michel et al., 2006).

The successful eradication of bovine TB from livestock in countries with a wildlife reservoir is likely to require focusing on the wildlife reservoir(s) of $M$. bovis infection (Palmer, 2007). Current methods of diagnosis in live animals, such as the intradermal tuberculin test or interferon-gamma (IFN- $\gamma$ ) release assays, are not fully validated for species other than cattle (Monaghan et al., 1994). Rapid and accurate assays that could be used in a variety of M. bovissusceptible mammals under field conditions would significantly improve wildlife TB surveillance efforts worldwide.

Prior studies have demonstrated the utility of membrane-based assays to detect specific antibodies during TB in cattle (Waters et al., 2006), cervids (Waters et al., 2004, 2005), elephants (Lyashchenko et al., 2006), camelids (Wernery et al., 2007; Lyashchenko et al., 2007a,b), and tapirs (Moser et al., 2008). The objectives of the present study were to (1) characterize the antibody responses of wild mammals infected with $M$. bovis, including badgers, deer, possums, and wild boar, (2) evaluate the usefulness of a lateral-flow test under field conditions, and (3) determine if a single serologic assay can be used for TB surveillance in a variety of different wildlife host species.

\section{Methods}

\subsection{Animals and samples}

Sera were collected from Eurasian badgers in Great Britain, white-tailed deer in the United States, brushtail possums in New Zealand, and wild boar in Spain and Portugal (Table 1).

Badger sera were obtained from two sources: (1) 1464 animals killed as part of the Randomised Badger Culling Trial (RBCT) (Donnelly et al., 2007), and (2) 68 animals captured, bled, and released as part of an ongoing ecological study by the Central Science Laboratory (CSL) in Woodchester Park, south-west

Table 1

Study populations

\begin{tabular}{llcc}
\hline Species & Institute, country & \multicolumn{2}{c}{ Number of animals } \\
\cline { 3 - 4 } & & TB & Control \\
\hline Badger & VLA, UK & 386 & 1078 \\
& CSL, UK & 68 & 0 \\
\multirow{2}{*}{ Deer } & MDNR, USA & 9 & 425 \\
& NADC, USA & $19^{\mathrm{a}}$ & $10^{\mathrm{b}}$ \\
\multirow{2}{*}{ Possum } & AgR HRI, New Zealand & 38 & 91 \\
Wild boar & IREC, Spain & 50 & 50 \\
& ICVS, Portugal & 14 & $63^{\mathrm{c}}$
\end{tabular}

\footnotetext{
a Inoculated with $M$. bovis intratonsilarly.

b Includes three animals experimentally infected with $M$. avium subsp. paratuberculosis.

c Includes three animals with $M$. avium and five animals with other non-TB mycobacteria identified by culture and PCR at necropsy.
} 
England (Chambers et al., 2008). All work with animals was conducted under licenses issued by the Home Office, UK, following ethical clearance by the VLA and CSL. All sera were stored frozen at $-20{ }^{\circ} \mathrm{C}$ until used for testing. Each badger from the RBCT was subjected to routine post-mortem examination and culture for the presence of M. bovis as described in Sawyer et al. (2007). The infection status of Woodchester Park badgers was determined by bacterial culture of clinical specimens (feces, urine, sputum, purulent exudate from abscesses, and bite wound swabs) collected from anaesthetized animals (Clifton-Hadley et al., 1993; Delahay et al., 2000). Since Woodchester Park badgers were live-sampled, only those animals excreting $M$. bovis were included in the present study.

Deer samples were obtained from experimentally infected animals at different stages of disease. Whitetailed deer (1-3 years of age) were either raised within a TB-free herd at the National Animal Disease Center (NADC), Ames, Iowa, USA, or obtained from farmed herds with no history of TB. Groups consisted of seven non-infected animals, three deer inoculated with $M$. avium subsp. paratuberculosis, and 19 deer inoculated via the intratonsilar route with various doses of $M$. bovis $\left(3 \times 10^{2}-2 \times 10^{8}\right.$ colony-forming units), as described previously (Waters et al., 2004; Palmer et al., 2007). All animals were euthanized at 4-11 months post-infection. Blood, diaphragm fluid and aqueous humor were collected during necropsy of experimentally infected deer. Specimens were extracted from diaphragms by freeze/thaw and mechanical disruption (using a garlic press). Aqueous humor was obtained by fine needle aspiration. Various tissues were collected for bacteriologic culture and microscopic examination. Disease was confirmed at necropsy in each infected deer by the presence of gross lesions, histopathological examination, and mycobacterial culture. The Institutional Animal Care and Use Committee approved protocols detailing procedures and animal care prior to initiation of the experiments.

In addition, fresh whole blood samples were collected from 434 free-ranging white-tailed deer in Michigan State where M. bovis infection is persistent in wild deer (Schmitt et al., 1997). The deer enrolled in the study inhabited the "core" area of the Michigan TB outbreak area (O'Brien et al., 2002). Blood samples were obtained from four sources: (1) culls of free-ranging deer conducted by hunters during 2005/
2006 and 2006/2007 winter seasons as part of herdhealth checks; (2) depopulation of a fenced captive deer shooting preserve in late 2006 following culture confirmation of grossly lesioned M. bovis-positive deer; (3) nuisance deer shot on cattle farms under disease control permits; and (4) deer tested as part of an ongoing live trap/test/cull project. Tissue samples used for culture included medial retropharyngeal lymph nodes, parietal pleura and lungs.

A group of brushtail possums naturally infected with $M$. bovis consisted of 29 animals captured at Castlepoint, Wairarapa and nine possums from the Orongorongo Valley near Wellington. All these had macroscopic TB lesions, from which $M$. bovis was cultured. Blood was collected from all of the animals immediately prior to euthanasia. A negative control group included 91 possums captured in Manawatu, an area of New Zealand that is free of bovine TB in domestic livestock and wild animals.

Hunter-harvested wild boar were sampled in Spain between November 1999 and February $2005(n=100)$ and in Portugal between December 2005 and January $2007(n=77)$. Various lymph nodes were examined for gross lesions and cultured for M. bovis as described previously (Gortázar et al., 2003; Martin-Hernando et al., 2007). Portuguese mycobacterial isolates were identified by PCR for a panel of selected genes: $16 \mathrm{~S}$ RNA, IS1081, Rv3120, Rv1510, and IS1245, and confirmed by spoligotyping. According to Huard et al. (2003) and Bartos et al. (2006), this set of genes allows for differentiation between $M$. bovis or other members of the M. tuberculosis complex and M. avium or other non-TB mycobacteria.

\subsection{Multiantigen print immunoassay (MAPIA)}

We used a panel of 12 mycobacterial antigens including 8 purified recombinant proteins (ESAT-6, CFP10, MPB64, MPB59, MPB70, MPB83, Acr1, and the $38 \mathrm{kDa}$ protein), two protein fusions (CFP10/ ESAT-6 and Acr1/MPB83), and two native antigens, bovine protein purified derivative (B-PPD) and $M$. bovis culture filtrate (MBCF). MAPIA was performed as described previously (Lyashchenko et al., 2000). Briefly, antigens were immobilized on a nitrocellulose membrane (Schleicher \& Schuell, Keene, N.H.) at a protein concentration of $0.05 \mathrm{mg} / \mathrm{ml}$ using a semiautomatic micro-aerosolization device (Linomat IV, 
Camag Scientific Inc., Wilmington, Delaware) to generate invisible parallel bands. After antigen printing, the membrane was cut into $3 \mathrm{~mm}$ wide strips, perpendicular to the antigen bands, so that each strip carried all antigens. Strips were blocked for $1 \mathrm{~h}$ with $1 \%$ non-fat skimmed bovine milk in phosphatebuffered saline containing $0.05 \%$ Tween 20 and then incubated with individual serum samples diluted 1:50 in blocking solution for $1 \mathrm{~h}$ at room temperature. After washing, the strips were incubated for $1 \mathrm{~h}$ with peroxidase-conjugated protein $\mathrm{G}$ (deer, wild boars) or protein A (badgers, possums) diluted 1:1000 (Kirkegaard \& Perry Laboratories), and subsequently washed again. IgG antibodies bound to immobilized antigens were visualized with 3,3',5,5'-tetramethyl benzidine (Kirkegaard \& Perry Laboratories). MAPIA results were read visually, with a band of any intensity being considered as a positive reaction.

\subsection{Rapid test (RT)}

A simple and rapid antibody detection assay was developed by Chembio Diagnostic Systems, Inc. using colored latex-based lateral-flow technology and a cocktail of selected M. bovis antigens including ESAT6, CFP10, and MPB83 (Greenwald et al., 2003; Waters et al., 2006). Serum specimens were tested for the presence of specific antibody as previously described (Lyashchenko et al., 2006). Results were read at 20 min after adding sample buffer. Any visible band in the test area of the RT, in addition to the control line, was considered an antibody positive result, whereas no band in the test area in addition to the visible control line was considered a negative result.

\subsection{Data analysis}

Diagnostic performance of the RT was evaluated against the gold standard of $M$. bovis culture by calculating test sensitivity, specificity, and accuracy (\% of RT results in agreement with TB status determined by culture) using available software (Lowry, 2007) and reported with the $95 \%$ confidence interval (CI). Test of significance between proportions (Fisher's exact test) and the calculation of odds ratio were performed using GraphPad InStat version 3.00 for Windows 95, GraphPad Software, San Diego California USA, www.graphpad.com. The statistical significance of the proportion of antibody detection rate in lesion positive wild boar in relation to those without visible lesions was performed by Chi-square tests (SPSS 11.0 Statistical Program).

\section{Results}

\subsection{Antibody responses and antigen recognition}

To compare antibody responses to $M$. bovis infection in different hosts, serum samples of all animals (possums) or of randomly selected culture-positive and culture-negative animals from naturally infected populations (badgers, deer, wild boar) were tested by MAPIA. Fig. 1 provides representative examples of the individual antigen reactivity patterns in each of the four mammal species. Table 2 shows the frequencies of IgG reactivity to $M$. bovis antigens found in infected and control animals. The MAPIA results confirmed our previous observations that MPB83 protein is serodominant in badgers with $M$. bovis infection and in experimentally infected white-tailed deer (Greenwald et al., 2003; Waters et al., 2004). The present study further revealed that this molecule is the most reactive antigen in brushtail possums and wild boar. In the naturally infected animals, the MPB83 seroreactivity rates ranged from $34 \%$ in possums to $89 \%$ in deer, whereas in culture-negative controls it varied from $1 \%$ in deer to $10 \%$ in badgers. ESAT- 6 and CFP10 antigens were the second and third most frequently recognized antigen in the MAPIA in all the species, except for wild boar. MPB70 protein elicited serological responses in greater numbers of infected wild boar (68\%) than did ESAT-6 (58\%) or CFP10 (52\%), although levels of MPB70 antibodies (evaluated visually by band intensity) were commonly lower than those of ESAT-6, CFP10, or MPB83 antibodies (Fig. 1). The other single proteins of $M$. bovis used in MAPIA reacted with variable numbers of sera from infected animals, ranging from $0 \%$ to $44 \%$. Significant seroreactivity was found for MBCF, with a few M. bovis-infected animals displaying antibody only to this antigen (Fig. 1, B4). However, the crude native preparation of M. bovis showed high rates of false-positive results (from $10 \%$ in badgers to $26 \%$ in deer).

Heterogeneous antigen recognition patterns were observed in each host species, so that there was no 
(A)

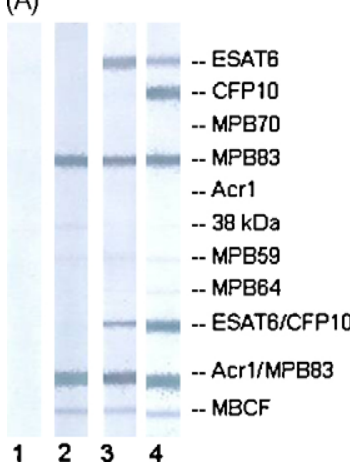

(B)

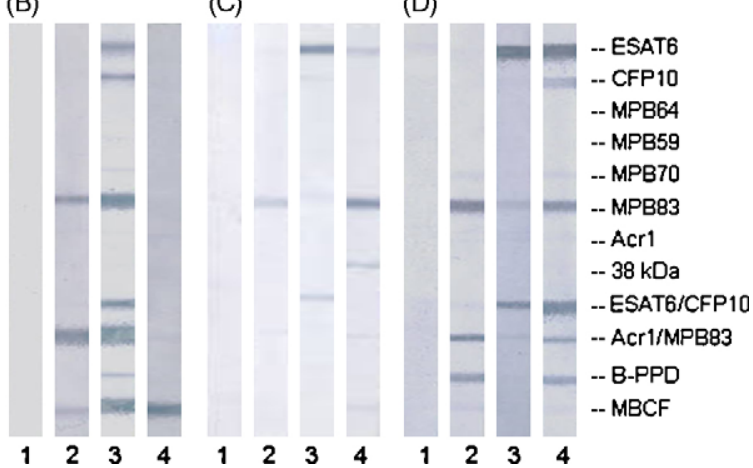

Fig. 1. Antibody responses detected by MAPIA in Eurasian badgers (A), white-tailed deer (B), brushtail possums (C), and European wild boar (D) naturally infected with M. bovis. Antigens printed onto nitrocellulose membrane, as described in Section 2, are indicated on the right. One control serum from culture-negative animal (strip 1) and three sera from different culture-positive animals (strips 2-4) were selected to show variable antigen recognition patterns in each host species. Visible bands of any intensity observed with certain antigen are IgG antibody positive reactions with respective antigens.

single antigen target common to all seropositive animals. It was demonstrated that the serological performance of the two antigen fusion proteins, CFP10/ESAT-6 and Acr1/MPB83, reflected the reactivity of the corresponding single antigens (Fig. 1). Subjective evaluations of the MAPIA band intensities and the numbers of antigens recognized by each animal in this study suggested that the strongest antibody responses were found in wild boars, whereas possums produced relatively weak antibody responses to $M$. bovis infection.

\subsection{Antibody detection by rapid test}

Serological evaluation of the RT revealed variable diagnostic performance when used in different host species (Table 3). Higher test sensitivity and specificity were found for deer and wild boar, compared to those observed in badgers and possums. The overall accuracy of the test ranged from $74 \%$ in possums to $97 \%$ in deer. When the diagnostic sensitivity was analyzed separately for deer with experimental and natural M. bovis infections, a lower rate of serological detection was found in the latter group (67\%) than in animals inoculated intratonsilarly with high dose of $M$ bovis (79\%). To further gauge the RT specificity, serum samples from three deer developing experimental paratuberculosis (all three had strong antibody responses, as previously shown by Palmer et al., 2007) and from eight wild boar naturally infected with M. avium or other non-TB mycobacteria were tested. None of these 11 animals produced a positive RT result.

Table 2

Seroreactivity rates (\%) of $M$. bovis antigens obtained in MAPIA with sera from naturally infected and uninfected animals

\begin{tabular}{|c|c|c|c|c|c|c|c|c|}
\hline \multirow[t]{2}{*}{ Antigen } & \multicolumn{2}{|l|}{ Badger } & \multicolumn{2}{|l|}{ Deer } & \multicolumn{2}{|l|}{ Possum } & \multicolumn{2}{|c|}{ Wild boar } \\
\hline & $\begin{array}{l}\text { TB } \\
(n=15)\end{array}$ & $\begin{array}{l}\text { Control } \\
(n=29)\end{array}$ & $\begin{array}{l}\text { TB } \\
(n=9)\end{array}$ & $\begin{array}{l}\text { Control } \\
(n=98)\end{array}$ & $\begin{array}{l}\text { TВ } \\
(n=38)\end{array}$ & $\begin{array}{l}\text { Control } \\
(n=91)\end{array}$ & $\begin{array}{l}\text { TВ } \\
(n=50)\end{array}$ & $\begin{array}{l}\text { Control } \\
(n=50)\end{array}$ \\
\hline MPB83 & 67 & 10 & 89 & 1 & 34 & 3 & 78 & 2 \\
\hline ESAT-6 & 27 & 0 & 67 & 2 & 21 & 1 & 58 & 8 \\
\hline CFP10 & 13 & 0 & 56 & 1 & 3 & 4 & 52 & 2 \\
\hline MPB70 & 7 & 0 & 44 & 0 & 2 & 0 & 68 & 0 \\
\hline $38 \mathrm{kDa}$ & 7 & 0 & 11 & 1 & 2 & 3 & 30 & 0 \\
\hline Acr1 & 7 & 0 & 22 & 0 & 0 & 1 & 22 & 0 \\
\hline MPB64 & 13 & 0 & 11 & 1 & 0 & 0 & 2 & 0 \\
\hline MPB59 & 27 & 7 & 44 & 3 & 0 & 0 & 0 & 0 \\
\hline MBCF & 53 & 10 & 89 & 26 & 34 & 20 & 44 & 12 \\
\hline
\end{tabular}


Table 3

Diagnostic performance of rapid test in different host species

\begin{tabular}{lllll}
\hline Species & $\begin{array}{l}\text { Prevalence of infection }(\%) \\
(95 \% \text { CI })\end{array}$ & $\begin{array}{l}\text { Sensitivity }(\%) \\
(95 \% \text { CI })\end{array}$ & $\begin{array}{l}\text { Specificity }(\%) \\
(95 \% \text { CI })\end{array}$ & $\begin{array}{l}\text { Accuracy }(\%) \\
(95 \% ~ C I)\end{array}$ \\
\hline Badger & $29.6(27.6-32.2)$ & $50.7(46.0-55.3)$ & $93.1(91.4-94.5)$ & $80.5(78.5-82.5)$ \\
Deer & $6.0^{\mathrm{a}}(4.1-8.7)$ & $75.0(54.8-88.6)$ & $98.9(97.2-99.6)$ & $97.4(95.4-98.6)$ \\
Possum & $29.5(21.9-38.2)$ & $44.7(29.0-61.5)$ & $85.7(76.4-91.9)$ & $73.6(65.0-80.8)$ \\
Wild boar & $36.2(29.2-43.7)$ & $76.6(64.0-85.9)$ & $97.3(91.9-99.3)$ & $89.8(84.2-93.7)$ \\
\hline
\end{tabular}

${ }^{\text {a }}$ Calculated prevalence of $M$. bovis infection is not representative for wild deer populations, as the TB group in this study included experimentally infected deer.

\subsection{Antibody in various types of biological samples}

Serum, plasma, fresh whole blood, diaphragm fluid, and aqueous humor were collected from three white-tailed deer experimentally infected with $M$. bovis and one non-infected deer. All the samples from the infected deer, except for the aqueous humor, yielded positive responses (Table 4). The intensity of RT reactions obtained with plasma, whole blood, and diaphragm fluid were comparable to that found for serum samples. No antibody reactivity was detected in any of the biological samples collected from the control deer. The MAPIA demonstrated that the antigen recognition patterns of antibodies found in diaphragm fluid and serum were similar (Fig. 2).

The use of whole blood in RT was more extensively evaluated in the Michigan study where samples were collected from 434 deer and tested under field conditions, followed by testing sera from the same animals in a blind-coded fashion. Nine deer were found to have TB lesions, from which M. bovis was cultured. Six of the infected animals were RT-reactive when serum samples were used, of which five deer produced antibody positive results with whole blood samples as well. Overall, the concordance between use of serum and whole blood was $96.8 \%$ (94.5-98.2 at $95 \% \mathrm{CI}$ ).

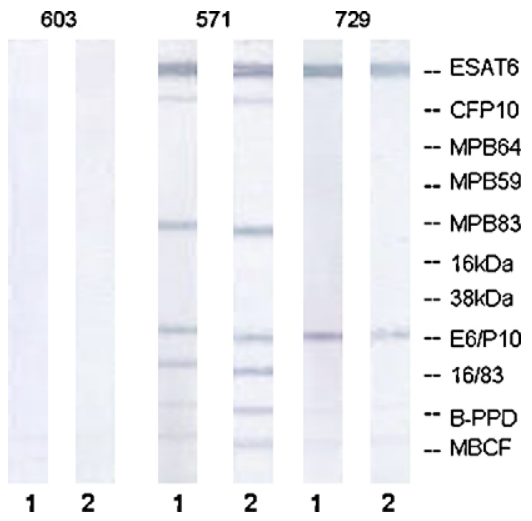

Fig. 2. MAPIA results obtained with sera (strip 1) and diaphragm fluids (strip 2) of white-tailed deer experimentally infected with $M$. bovis (571 and 729) and negative control (603). Antigens printed onto nitrocellulose membrane, as described in Section 2, are indicated on the right. Visible bands of any intensity observed with certain antigen are $\operatorname{IgG}$ antibody positive reactions with respective antigens.

\subsection{Serology and severity of disease}

A close association between strong antibody responses and the presence of gross lesions in wild boar infected with $M$. bovis was noticed (Table 5). While the overall sensitivity of the RT was $77 \%$, the antibody detection rate in the boar with macroscopic lesions was five times higher $(83 \%)$ than that in

Table 4

Antibody detection by rapid test in various types of biological samples from white-tailed deer experimentally inoculated with $M$. bovis

\begin{tabular}{lllllll}
\hline Group & Animal ID no. & Serum & Plasma & Whole blood & Diaphragm juice & Aqueous humor \\
\hline Uninfected & 603 & - & - & - & - & - \\
M. bovis-infected & 528 & ++ & ++ & ++ & ++ & - \\
& 571 & +++ & +++ & +++ & ++ & - \\
& 729 & ++ & ++ & + & ++ & - \\
\hline
\end{tabular}

Test results were scored visually as strong $(+++)$, moderate $(++)$, or weak $(+)$ reactions, or non-reactive $(-)$. 
Table 5

Association between the presence of gross lesions and positive rapid test results in infected wild boar

\begin{tabular}{llll}
\hline Test & Visible lesions & No visible lesions & Total \\
\hline RT-positive & 48 & 1 & 49 \\
RT-negative & 10 & 5 & 15 \\
Total & 58 & 6 & 64 \\
\hline
\end{tabular}

animals without visible lesions (17\%). The difference was highly significant $\left(\chi^{2} 13.24\right.$, d.f. $1, p=0.0003$; $p=0.002$, Fisher's exact test), with an odds ratio of 24 (2.5-228.4, 95\% CI). In other words, the boar with gross lesions were on average 24 times more likely to be positive in the RT than those without visible lesions. With samples from Portugal, where most of the $M$. bovis-infected wild boar without lesions originated, all 10 animals with gross lesions were RT-reactive, whereas none of the four culture-positive boar without lesions had detectable antibodies.

\section{Discussion}

The present study characterized serological responses in infected animals of four species of wild mammals that are implicated in the persistence of $M$. bovis infection in cattle in different countries. Our results demonstrated that tuberculous badgers, whitetailed deer, brushtail possums, and wild boar produced variable levels of IgG antibodies against several $M$. bovis antigens. Importantly, the responses could be detected in each host by a recently developed 'pointof-care'-type lateral-flow test for bovine TB (Lyashchenko et al., 2006; Waters et al., 2006). MAPIA revealed antibodies to multiple proteins of $M$. bovis with heterogeneous antigen recognition patterns observed in the infected animals. These findings are in agreement with our previous reports on human TB serology (Lyashchenko et al., 2000) as well as other mammal species susceptible to organisms of the $M$. tuberculosis complex (Lyashchenko et al., 2004, 2006, 2007a,b; Waters et al., 2005, 2006). The serodominance of the MPB83 protein known to elicit the strongest antibody responses to experimental $\mathrm{TB}$ infection in cattle, badger, and deer (Lesellier et al., 2008; Lyashchenko et al., 2004; Waters et al., 2004) was extended in the present study to naturally infected animals as well as other, previously untested species (possums and wild boar).

Antibody detection methods are generally simple, rapid, and inexpensive. The lateral-flow assay format offers important features that make the RT evaluated in the present study an attractive screening tool for field applications. This is an easy-to-perform animal-side disposable kit which can use serum, plasma, whole blood, or other samples to provide "yes-or-no" visual read-outs within $15-20 \mathrm{~min}$. The test speed is particularly useful for wildlife surveillance where a "euthanize or release" decision may be needed quickly on a physically restrained animal. The RT kits are stable at room temperature for up to 18-24 months, and they do not require refrigeration for storage, a power source, equipment, laboratory environment, or skilled personnel to perform the assay and interpret results. The test is suitable for use under field conditions, as it can be minimally affected by extremes of ambient temperature. Test results are unambiguous; high levels of reproducibility (lot-tolot, operator-to-operator, laboratory-to-laboratory, and day-to-day) have been demonstrated in our unpublished studies, with the overall precision of $98.5 \%$ (Lci $=96.3 \%$ ). Although the immunoassay itself is straightforward, obtaining the actual blood sample for testing may be less practical for some species (e.g. badgers) than others (e.g. deer). The requirement to anaesthetise an animal in order to obtain a blood sample may complicate surveillance or control programmes but not necessarily render them unfeasible.

The RT described here has been designed to detect specific antibodies of three major classes, $\operatorname{IgM}, \mathrm{IgG}$, and $\operatorname{IgA}$. Moreover, the immunoassay format makes it independent of antibody origin, as long as the molecule has at least two functional antigen-binding sites. This multi-host diagnostic potential was demonstrated in the present study as an additional important feature of the testing technology. In fact, the majority of animals in naturally infected populations of the four species studied were correctly identified by the same device. The data described here suggest that the use of such a quick and easy field test may accommodate wildlife surveillance and bovine TB control strategies in many countries where persisting $M$. bovis infection in free-ranging wild mammals poses a constant threat to livestock. 
Suboptimal RT sensitivities found in this study for badgers and possums (51\% and $45 \%$, respectively) are in line with previous attempts to detect antibodies to M. bovis in these animals (Buddle et al., 1995; Chambers et al., 2002, 2008; Greenwald et al., 2003). The strong IgG responses in wild boar appear in agreement with the reported observation that Ig heavy and light chains were up-regulated during $M$. bovis infection (Naranjo et al., 2006). This finding offers the possibility of using serology for large-scale testing of wildlife in epidemiological surveys. Additionally, the availability of the RT makes test-and-cull schemes an attractive approach in situations where mere reduction of wild populations is not satisfactory.

In wild boar, for which pathology data were available for analysis, strong antibody responses were commonly associated with the presence of gross lesions. Similar observations have been previously made for other host species (Chambers et al., 2002; Lesellier et al., 2008; Lyashchenko et al., 2004; Waters et al., 2004). This supports the view that serological assays may predominantly target animals in the advanced stages of disease progression typically characterized by higher rates of shedding, which may reflect enhanced potential for transmission (Chambers et al., 2008).

White-tailed deer experimentally infected with $M$. bovis produced antibodies that could be found by MAPIA and RT in serum, whole blood and other biological fluids equally well. The demonstrated feasibility of antibody detection from non-serological samples, such as tissue exudates from animal carcasses, provides a useful option for RT application under field conditions when a fresh blood specimen cannot be collected, although a recent badger study suggested that sample quality could affect the diagnostic performance of the RT by reducing its sensitivity if haemolized or lipaemic blood specimens were used (Chambers et al., 2008).

Although deer MAPIA analyses showed no significant difference between experimental and natural $M$. bovis infection in terms of the magnitude of antibody responses and variable antigen recognition profiles, the RT sensitivity appeared higher in animals inoculated intratonsilarly, when compared to that found in Michigan free-ranging deer. This difference may be due to (1) the use of high dose of $M$. bovis for most of the experimentally infected deer, and (2) collection of blood samples for serological testing at certain time-points of well-synchronized infection when most of the infected animals could have detectable antibody responses already developed. Recent studies on nonhuman primates found no difference in the diagnostic performance of similar serologic assays between natural and low-dose experimental infections with $M$. tuberculosis or $M$. bovis (Lyashchenko et al., 2007a).

As was shown for wild boar, our unpublished field studies on Michigan white-tailed deer also suggest that the RT is most effective at detecting animals with severe disseminated TB (based on post-mortem examination and culture) and that it typically yields a strong positive result within 3-5 min. Because deer with more advanced disease are most likely to be excreting $M$. bovis in significant quantities (Schmitt et al., 1997; Palmer, 2007), they pose the greatest risk of exposure to uninfected wildlife and livestock. Consequently, they are the most important animals to cull from the population. A similar strategy may also be appropriate for other countries with established wildlife reservoirs of $M$. bovis infection. Thus, serologic assays such as the RT may provide useful screening tools for controlling bovine TB in populations of different wildlife species, especially where the sensitivity is at its highest and the practical limitations can be overcome.

\section{Acknowledgments}

The authors are grateful to Peter Andersen and Jim McNair for kindly providing certain antigens used in this study. Badger samples were taken under projects funded by the Department for Environment, Food, and Rural Affairs (Defra), UK. The authors acknowledge the support of staff from CSL, VLA Starcross, Defra Wildlife Unit, and permission from the Independent Scientific Group for use of sera from the RBCT. Spanish wild boar samples were obtained with support from MEC Plan Nacional AGL2005-07401 and Santander - Fundación M. Botín.

\section{References}

Bartos, M., Hlozek, P., Svastova, P., Dvorska, L., Bull, T., Matlova, L., Parmova, I., Kuhn, I., Stubbs, J., Morakova, M., Kintr, J., 
Beran, V., Melicharek, I., Ocepek, M., Pavlik, I., 2006. Identification of members of Mycobacterium avium species by AccuProbes, serotyping, and single IS900, IS901, IS1245 and IS901flanking region PCR with internal standards. J. Microbiol. Methods 64, 333-345.

Buddle, B.M., Nolan, A., McCarthy, A.R., Heslop, J., Aldwell, F.E., Jackson, R., Pfeiffer, D.U., 1995. Evaluation of three serological assays for the diagnosis of Mycobacterium bovis infection in brushtail possums. N.Z. Vet. J. 43, 91-95.

Chambers, M.A., Pressling, W.A., Cheeseman, C.L., Clifton-Hadley, R.S., Hewinson, R.G., 2002. Value of existing serological tests for identifying badgers that shed Mycobacterium bovis. Vet. Microbiol. 86, 183-189.

Chambers, M.A., Crawshaw, T., Waterhouse, S., Delahay, R., Hewinson, R.G., Lyashchenko, K.P., 2008. Validation of the BrockTB STAT-PAK assay for the detection of tuberculosis in Eurasian badgers (Meles meles) and influence of disease severity on diagnostic accuracy. J. Clin. Microbiol. 46, 1498-1500.

Clifton-Hadley, R.S., Wilesmith, J.W., Stuart, F.A., 1993. Мycobacterium bovis in the European badger (Meles meles): epidemiological findings in tuberculous badgers from a naturally infected population. Epidemiol. Infect. 111, 9-19.

Coleman, J.D., Coleman, M.C., Warburton, B., 2006. Trends in the incidence of tuberculosis in possums and livestock, associated with differing control intensities applied to possum populations. N.Z. Vet. J. 54, 52-60.

Corner, L.A., 2006. The role of wild animal populations in the epidemiology of tuberculosis in domestic animals: how to assess the risk. Vet. Microbiol. 112, 303-312.

Cosivi, O., Grange, J.M., Daborn, C.J., Raviglione, M.C., Fujikura, T., Cousins, D., Robinson, R.A., Huchzermeyer, H.F., de Kantor, I., Meslin, F.X., 1998. Zoonotic tuberculosis due to Mycobacterium bovis in developing countries. Emerg. Infect. Dis. 4, 59-70.

Cousins, D.V., 2001. Mycobacterium bovis infection and control in domestic livestock. Dev. Sci. tech. Off. Int. Epiz. 20, 71-85.

Delahay, R.J., Langton, S., Smith, G.C., Clifton-hadley, R.S., Cheeseman, C.L., 2000. The spatio-temporal distribution of Mycobacterium bovis (bovine tuberculosis) infection in a high-density badger population. J. Anim. Ecol. 69, 428-441.

Donnelly, C.A., Wei, G., Johnston, W.T., Cox, D.R., Woodroffe, R., Bourne, F.J., Cheeseman, C.L., Clifton-Hadley, R.S., Gettinby, G., Gilks, P., Jenkins, H.E., Le Fevre, A.M., McInerney, J.P., Morrison, W.I., 2007. Impacts of widespread badger culling on cattle tuberculosis: concluding analyses from a large-scale field trial. Int. J. Infect. Dis. 11, 300-308.

Gortázar, C., Vicente, J., Gavier-Widen, D., 2003. Pathology of bovine tuberculosis in the European wild boar. Vet. Rec. 152, 779-780.

Greenwald, R., Esfandiari, J., Lesellier, S., Houghton, R., Pollock, J., Aagaard, C., Andersen, P., Hewinson, R.G., Chambers, M., Lyashchenko, K., 2003. Improved serodetection of Mycobacterium bovis infection in badgers (Meles meles) using multiantigen formats. Diagn. Microbiol. Infect. Dis. 46, 197-203.

Griffin, J.M., Williams, D.H., Kelly, G.E., Clegg, T.A., O’Boyle, I., Collins, J.D., More, S.J., 2005. The impact of badger removal on the control of tuberculosis in cattle herds in Ireland. Prev. Vet. Med. 67, 237-266.
Huard, R., Lazzarini, L., Butler, W., van Soolingen, D., Ho, J., 2003. PCR-based method to differentiate the subspecies of the Mycobacterium tuberculosis complex on the basis of genomic deletions. J. Clin. Microbiol. 41, 1637-1650.

Lesellier, S., Corner, L., Costello, E., Sleeman, P., Lyashchenko, K., Greenwald, R., Esfandiari, J., Singh, M., Hewinson, R.G., Chambers, M., Gormley, E., 2008. Antigen specific immunological responses of badgers (Meles meles) experimentally infected with Mycobacterium bovis. Vet. Immunol. Immunopathol. 122, 35-45.

Lowry, R., 2007. VassarStats: web site for statistical computation. Clinical calculator 1. From an observed sample: estimates of population prevalence, sensitivity, specificity, predictive values, and likelihood ratios. Vassar College, Poughkeepsie, New York, (http://faculty.vassar.edu/lowry/VassarStats.html), last accessed 5 July 2007.

Lyashchenko, K.P., Singh, M., Colangeli, R., Gennaro, M.L., 2000. A multiantigen print immunoassay for the serological diagnosis of infectious diseases. J. Immunol. Methods 242, 91-100.

Lyashchenko, K., Whelan, A.O., Greenwald, R., Pollock, J.M., Andersen, P., Hewinson, R.G., Vordermeier, H.M., 2004. Association of tuberculin-boosted antibody responses with pathology and cell-mediated immunity in cattle vaccinated with Mycobacterium bovis BCG and infected with M. bovis. Infect. Immun. 72, 2462-2467.

Lyashchenko, K.P., Greenwald, R., Esfandiari, J., Olsen, J.H., Ball, R., Dumonceaux, G., Dunker, F., Buckley, C., Richard, M., Murray, S., Payeur, J.B., Andersen, P., Pollock, J.M., Mikota, S., Miller, M., Sofranko, D., Waters, W.R., 2006. Tuberculosis in elephants: antibody responses to defined antigens of Mycobacterium tuberculosis, potential for early diagnosis, and monitoring of treatment. Clin. Vaccine Immunol. 13, 722-732.

Lyashchenko, K.P., Greenwald, R., Esfandiari, J., Greenwald, D., Nacy, C.A., Gibson, S., Didier, P.J., Washington, M., Szczerba, P., Motzel, S., Handt, L., Pollock, J.M., McNair, J., Andersen, P., Langermans, J.A.M., Verreck, F., Ervin, S., Ervin, F., McCombs, C., 2007a. PrimaTB STAT-PAK assay, a novel rapid lateral-flow test for tuberculosis in nonhuman primates. Clin. Vaccine Immunol. 14, 1158-1164.

Lyashchenko, K.P., Greenwald, R., Esfandiari, Meylan, M., Hengrave Burri, I., Zanolari, P., 2007b. Antibody responses in New World camelids with tuberculosis caused by Mycobacterium microti. Vet. Microbiol. 125, 265-273.

Martin-Hernando, M.P., Hofle, U., Vicente, J., Ruiz-Fons, F., Vidal, D., Barral, M., Garrido, J.M., de la Fuente, J., Gortazar, C., 2007. Lesions associated with Mycobacterium tuberculosis complex infection in the European wild boar. Tuberculosis 87, 360-367.

Michel, A.L., Bengis, R.G., Keet, D.F., Hofmeyr, M., Klerk, L.M., Cross, P.C., Jolles, A.E., Cooper, D., Whyte, I.J., Buss, P., Godfroid, J., 2006. Wildlife tuberculosis in South African conservation areas: implications and challenges. Vet. Microbiol. 112, 91-100.

Monaghan, M.L., Doherty, M.L., Collins, J.D., Kazda, J.E., Quinn, P.J., 1994. The tuberculin test. Vet. Microbiol. 40, 111-124.

Moser, I., Prodinger, W.M., Hotzel, H., Greenwald, R., Lyashchenko, K.P., Bakker, D., Gomis, D., Seidler, T., Ellenberger, C., Hetzel, U., Wuennemann, K., Moisson, P., 2008. Mycobac- 
terium pinnipedii: transmission from South American sea lion (Otaria byronia) to Bactrian camel (Camelus bactrianus bactrianus) and Malayan tapirs (Tapirus indicus). Vet. Microbiol. 127, 399-406.

Naranjo, V., Höfle, U., Vicente, J., Martin, M.P., Ruiz-Fons, F., Gortazar, C., Kocan, K.M., de la Fuente, J., 2006. Genes differentially expressed in oropharyngeal tonsils and mandibular lymph nodes of tuberculous and nontuberculous European wild boar naturally exposed to Mycobacterium bovis. FEMS Immunol. Med. Microbiol. 46, 298-312.

Naranjo, V., Gortazar, C., Vicente, J., de la Fuente, J., 2008. Evidence for the role of European wild boar as a reservoir of Mycobacterium tuberculosis complex. Vet. Microbiol. 127, 1-9.

O'Brien, D.J., Schmitt, S.M., Fierke, J.S., Hogle, S.A., Winterstein, S.R., Cooley, T.M., Moritz, W.E., Diegel, K.L., Fitzgerald, S.D., Berry, D.E., Kaneene, J.B., 2002. Epidemiology of Mycobacterium bovis in free-ranging white-tailed deer, Michigan, USA, 1995-2000. Prevent. Vet. Med. 54, 47-63.

O’Brien, D.J., Schmitt, S.M., Fitzgerald, S.D., Berry, D.E., Hickling, G.J., 2006. Managing the wildlife reservoir of Mycobacterium bovis: the Michigan, USA, experience. Vet. Microbiol. 112, 313-323.

Palmer, M.V., 2007. Tuberculosis: a reemerging disease at the interface of domestic animals and wildlife. Curr. Top. Microbiol. Immunol. 315, 195-215.

Palmer, M.V., Stabel, J.R., Waters, W.R., Bannantine, J.P., Miller, J.M., 2007. Experimental infection of white-tailed deer (Odocoileus virginianus) with Mycobacterium avium subsp. paratuberculosis. J. Wildl. Dis. 43, 597-608.

Porphyre, T., McKenzie, J., Stevenson, M., 2007. A descriptive spatial analysis of bovine tuberculosis in intensively controlled cattle farms in New Zealand. Vet. Res. 38, 465-479.
Schmitt, S.M., Fitzerald, S.D., Cooley, T.M., Bruning-Fann, C.S., Sullivan, L., Berry, D., Carlson, T., Minnis, R.B., Payeur, J.B., Sikarskie, J., 1997. Bovine tuberculosis in free-ranging whitetailed deer from Michigan. J. Wildl. Dis. 33, 749-758.

Sawyer, J., Mealing, D., Dalley, D., Dave, D., Lesellier, S., Palmer, S., Bowen-Davies, J., Crawshaw, T.R., Chambers, M.A., 2007. Development and evaluation of a test for tuberculosis in live European badgers (Meles meles) based on measurement of gamma interferon mRNA by real-time PCR. J. Clin. Microbiol. 45, 2398-2403.

Waters, W.R., Palmer, M.V., Bannantine, J.P., Whipple, D.L., Greenwald, R., Esfandiari, J., Andersen, P., McNair, J., Pollock, J.M., Lyashchenko, K.P., 2004. Antigen recognition by serum antibodies in white-tailed deer (Odocoileus virginianus) experimentally infected with Mycobacterium bovis. Clin. Diagn. Lab. Immunol. 11, 849-855.

Waters, W.R., Pamer, M.V., Bannantine, J.P., Greenwald, R., Esfandiari, J., Andersen, P., McNair, J., Pollock, J.M., Lyashchenko, K.P., 2005. Antibody responses in reindeer (Rangifer tarandus) infected with Mycobacterium bovis. Clin. Diagn. Lab. Immunol. 12, 727-735.

Waters, W.R., Palmer, M.V., Thacker, T.C., Bannantine, J.P., Vordermeier, H.M., Hewinson, R.G., Greenwald, R., Esfandiari, J., McNair, J., Pollock, J.M., Andersen, P., Lyashchenko, K.P., 2006. Early antibody responses to experimental Mycobacterium bovis infection of cattle. Clin. Vaccine Immunol. 13 , 648-654.

Wernery, U., Kinne, J., Jahans, K.L., Vordermeier, H.M., Esfandiari, J., Greenwald, R., Johnson, B., Ul-Hag, A., Lyashchenko, K.P., 2007. Tuberculosis outbreak in a dromedary racing herd and rapid serological detection of infected camels. Vet. Microbiol. $122,108-115$. 